Check for updates

Cite this: Phys. Chem. Chem. Phys., 2022, 24, 7768

Received 7th February 2022,

Accepted 8th March 2022

DOI: 10.1039/d2cp00616b

rsc.li/pccp

\section{Proton-phosphorous connectivities revealed by high-resolution proton-detected solid-state NMR $\dagger$}

\author{
Alexander A. Malär, (DD a Qu Sun, (DD ${ }^{b}$ Johannes Zehnder, ${ }^{a}$ Gerald Kehr, (D) b \\ Gerhard Erker (D) ${ }^{b}$ and Thomas Wiegand (D) $\ddagger \S^{* a}$
}

\begin{abstract}
Proton-detected solid-state NMR enables atomic-level insight in solid-state reactions, for instance in heterogeneous catalysis, which is fundamental for deciphering chemical reaction mechanisms. We herein introduce a phosphorus-31 radiofrequency channel in proton-detected solid-state NMR at fast magic-angle spinning. We demonstrate our approach using solid-state ${ }^{1} \mathrm{H} /{ }^{31} \mathrm{P}$ and ${ }^{1} \mathrm{H} /{ }^{13} \mathrm{C}$ correlation experiments at high magnetic fields (850 and $1200 \mathrm{MHz})$ and high spinning frequencies $(100 \mathrm{kHz})$ to characterize four selected $\mathrm{PH}$-containing compounds from the chemistry of phosphane-borane frustrated Lewis pairs. Frustrated Lewis pairs have gained high interest in the past years, particularly due to their capabilities of activating and binding small molecules, such as di-hydrogen, however, their analytical characterization especially in the solid state is still limited. Our approach reveals protonphosphorus connectivities providing important information on spatial proximity and chemical bonding within such compounds. We also identify protons that show strongly different chemical-shift values compared to the solution state, which we attribute to intermolecular ring-current effects. The most challenging example presented herein is a cyclotrimeric frustrate Lewis pair-associate comprising three crystallographically distinct phosphonium entities that are unambiguously distinguished by our approach. Such ${ }^{31} \mathrm{P}$ spin-filtered proton-detected NMR can be easily extended to other material classes and can strongly impact the structural characterization of reaction products of hydrogen-activated phosphane/ borane FLPs, heterogeneous catalysts and solid-state reactions in general.
\end{abstract}

\section{Introduction}

Solid-state nuclear magnetic-resonance (NMR) spectroscopy is an important player in unravelling the mechanisms of chemical reactions in the solid state and has been explored for instance in heterogeneous catalysis ${ }^{1,2}$ and mechanochemistry. ${ }^{3-5}$ Up to now, proton resonance lines at slow MAS frequencies $(10-20 \mathrm{kHz})$ were typically rather broad which is often associated with an incomplete suppression of the homonuclear dipolar coupling network by magic-angle spinning (MAS). ${ }^{6,7} \mathrm{We}$ herein introduce phosphorus-31 as an additional radiofrequency channel in proton-detected fast MAS experiments $(\geq 100 \mathrm{kHz})^{6-8}$ allowing the investigation of a variety of functionalized phosphorus-containing materials (for instance,

\footnotetext{
${ }^{a}$ Physical Chemistry, ETH Zurich, Vladimir-Prelog-Weg 2, 8093 Zurich, Switzerland. E-mail: thomas.wiegand@cec.mpg.de

${ }^{b}$ Organisch-Chemisches Institut, WWU Münster, Corrensstr. 40, 48149 Münster, Germany

$\dagger$ Electronic supplementary information (ESI) available. See DOI: 10.1039/d2cp00616b \# Current address: Max-Planck-Institute for Chemical Energy Conversion, Stiftstr. 34-36, 45470 Mülheim an der Ruhr, Germany.

$\S$ Current address: Institute of Technical and Macromolecular Chemistry, RWTH Aachen University, Worringerweg 2, 52074 Aachen, Germany.
}

heterogeneous catalysts, modified zeolites $^{9}$ or aluminophosphates ${ }^{10}$ ), as well as the characterization of biomolecular protein-nucleotide complexes. ${ }^{11}$ Compared to previously reported ${ }^{31} \mathrm{P}$-detected ${ }^{1} \mathrm{H}^{3}{ }^{31} \mathrm{P}$ heteronuclear correlation experiments (HETCOR) combined with rather high-power ${ }^{1} \mathrm{H}$ homonuclear decoupling performed at relatively slow MAS frequencies, ${ }^{9,12-15}$ the herein proposed ${ }^{1} \mathrm{H}$-detected ${ }^{31} \mathrm{P}-{ }^{1} \mathrm{H}$ correlation experiment at fast MAS benefits in particular from requiring small sample amounts $(<0.5 \mathrm{mg})$ and low-power decoupling. In addition, inverse detection schemes as used in solution (where one starts and ends with proton polarization) is turning into the method-of-choice at fast MAS frequencies due to the high sensitivity in ${ }^{1} \mathrm{H}$-detection of the NMR probes for small rotor diameters. ${ }^{16,17}$ In addition, fast MAS experiments pave the way for $J$-coupling based polarization transfers typically employed in solution thus closing more and more the gap between solution and solid-state NMR. Probably the biggest advantage is that proton-detected NMR directly accesses proton nuclear spins, which often are engaged in noncovalent interactions and are thus at the center of many molecular recognition processes. We demonstrate the potential of our proton-detected approach on molecules related to frustrated Lewis pair (FLP) chemistry.

The discovery of Frustrated Lewis Pairs (FLPs) and their investigation in a variety of reaction pathways was a milestone 
of main group chemistry in the past years and is still of high interest. ${ }^{18-27}$ This is particularly associated with their capabilities in activating and binding small molecules, with dihydrogen being probably the most important example. ${ }^{22,28-32}$ Structural characterization is typically performed by X-ray diffraction and solution-state NMR, although also the benefit of solid-state NMR has been reported, ${ }^{15,33-37}$ in particular for oligomeric systems. ${ }^{35,38,39}$ FLPs have recently also been reported in heterogeneous catalysis. ${ }^{32,37,40-43}$ Less is known about the reactivity of such FLPs in the solid state, which is different from that in solution (see for instance ${ }^{32}$ ), probably because the analytical characterization in the solid state is complicated. Thus, the improvement of structural characterization in the solid state is indispensable. ${ }^{32}$

The benefit in detecting protons in NMR experiments, e.g. due to the high gyromagnetic ratio, the $100 \%$ natural abundance and their use as local probes for probing non-covalent interactions, such as hydrogen bonds, ${ }^{44}$ motivates the development of MAS rotors operating at always faster MAS frequencies to narrow the lines as much as possible. The record in these days has been achieved employing cylindrical MAS rotors with a diameter of $0.5 \mathrm{~mm}$ (around $170 \mathrm{kHz}$ MAS). ${ }^{45-47}$ Protondetected NMR experiments at $100 \mathrm{kHz}$ MAS or above have so far been used mostly in biomolecular applications, ${ }^{4-58}$ but are also starting to gain importance in the field of materials sciences. ${ }^{6,47,59-62}$ In all of these applications, the resolution of ${ }^{1} \mathrm{H}$ MAS spectra benefits greatly from a reduction of the socalled homogeneous line-broadening associated with the proton-dipolar network ${ }^{6,63-65}$ at fast MAS frequencies. Note that also Redfield-type relaxation processes might contribute to the homogeneous linewidth in presence of large dynamic motions, for a detailed discussion of the different contributions to the proton linewidth, see ref. 65 and 66. Another important contribution to the proton linewidth, the so-called inhomogeneous contribution, is caused by an imperfect magnetic-field homogeneity (the magnet "shim"), magic-angle instabilities, ${ }^{67}$ structural disorder or anisotropic bulk magnetic susceptibility effects $^{61,68-71}$ and is not dependent on the MAS frequency. ${ }^{66}$ Besides fast MAS to achieve narrow proton resonances, homonuclear decoupling ${ }^{72-74}$ eventually also combined with doublequantum spectroscopy ${ }^{75}$ or the removal of the homogeneous broadening in constant-time experiments ${ }^{74}$ has been reported. An alternative approach revealing pure isotropic proton solidstate NMR spectra has been described recently based on computationally extrapolating the MAS-dependent linewidth to infinite MAS frequency. ${ }^{76}$

We herein show that in our selected series of $\mathrm{PH}-$ compounds, fast MAS already reduces the proton linewidth to such an extent that two-dimensional spin-diffusion (SD) based spectra already allow for resonance assignment in the solid state. The strongest improvement in proton linewidths is observed for protons in the strong-coupling regime, in which strong dipolar couplings with small chemical-shift differences are present, such as observed in methylene $\left(-\mathrm{CH}_{2}-\right)$ groups. ${ }^{7,70}$ In our study, we focus in particular on protons bound directly to the phosphorus in phosphonium or phosphane derivatives ${ }^{77}$ and present proton-detected cross-polarization based ${ }^{31} \mathrm{P},{ }^{1} \mathrm{H}$ correlation experiments applied as a spin filter to identify and assign the corresponding protons, especially in cases where the resolution in ${ }^{1} \mathrm{H}$ MAS spectra is still not sufficient to unambiguously assign them in 1D or homonuclear 2D spectra. Such correlation spectra even allow extracting ${ }^{31} \mathrm{P}-{ }^{1} \mathrm{H} J$-coupling constants ranging in-between 250 to $500 \mathrm{~Hz}$ in our examples. Our most challenging target molecule is a cyclotrimeric phosphane-borate FLP associate in which the macrocycle is composed out of 12 atoms. ${ }^{77}$ All three sites are distinguishable in our ${ }^{31} \mathrm{P}-{ }^{1} \mathrm{H}$ correlation spectra in contrast to experiments performed in solution. ${ }^{77}$ Combining the resolution improvement with the introduction of the phosphorous spins as new players in proton-detected spectra paves the way for using proton-detected solid-state NMR at fast MAS frequencies for further pushing structural characterization of organic molecules and functionalized materials in general. We could envision that ${ }^{31} \mathrm{P}$ spin-filtered proton-detected NMR will have great impact in the structural characterization of reaction products of hydrogen-activated phosphane/borane FLPs (particular in solid-state reactions), of solid-state reactions in general (e.g. in mechanochemistry), in heterogeneous catalysis particularly involving phosphine ligands, as well as in biomolecular applications, e.g. in nucleic acid or drug binding to proteins.

\section{Materials \& methods}

\section{Synthesis of compounds}

Compounds 1-4 have been synthesized and prepared as described in ref. 77 and 78. Ortho-Phospho-L-tyrosine has been purchased from Sigma Aldrich and was used without any further purification.

\section{Solid-state NMR}

${ }^{1} \mathrm{H}$ MAS and hPH solid-state NMR experiments have been conducted at $100 \mathrm{kHz}$ MAS and 20.0 T external magnetic-field strengths in a commercially available broadband $0.7 \mathrm{~mm}$ probe that can be tuned up to ${ }^{31} \mathrm{P}$. The probe was operating in a doubleresonance ${ }^{1} \mathrm{H}-\mathrm{X}$ mode, where the $\mathrm{X}$ channel was tuned to 344.3 MHz. ${ }^{1} \mathrm{H},{ }^{31} \mathrm{P}$ hard-pulse powers and $\mathrm{CP}$ conditions were optimized on $o$-phospho-L-tyrosine as an external standard and then used for the hPH experiments (double CP experiment with ${ }^{1} \mathrm{H}_{-}{ }^{31} \mathrm{P}$ and ${ }^{31} \mathrm{P}-{ }^{1} \mathrm{H}$ CP transfer steps) on compounds 1-4. The hCH spectrum was recorded at $28.2 \mathrm{~T}$ using $100 \mathrm{kHz}$ MAS in a tripleresonance $\mathrm{H} / \mathrm{C} / \mathrm{N} 0.7 \mathrm{~mm}$ probe. The spectra were referenced to 4,4dimethyl-4-silapentane-1-sulfonic acid (DSS) using the ${ }^{13} \mathrm{C}$ resonances of solid adamantane as an internal standard.

All samples were packed in the $0.7 \mathrm{~mm}$ rotors in a glove-box under argon atmosphere. The rotors were closed inside the glove-box. NMR pulse sequence and acquisition parameters for all experiments are collected in the experimental tables in the ESI, $\dagger$ section (Tables S2). Sample temperature was controlled during the experiments by setting VTU (variable temperature unit) temperatures to $260 \mathrm{~K}$ with a cooling gas flow of 400 liters per hour. Spectra were processed in Topspin (versions 3.5 and 4.0, Bruker Biospin), visualized and analyzed in ccpnmr 
(version 2.4.2). ${ }^{79-81} 2 \mathrm{D}{ }^{1} \mathrm{H}^{-1} \mathrm{H}$ experiments were processed with a shifted sine bell apodization function SSB $=2.5 / 3$ and automatic baseline correction. 2D hPH spectra were processed with $\mathrm{SSB}=2.5 . T_{2}^{\prime}\left({ }^{1} \mathrm{H}\right)$ experiments were recorded using Hahn-echo relaxation experiments with variable-echo time $\tau_{\text {echo }}$ ranging between $1 \mu \mathrm{s}-10 \mathrm{~ms}$. Relaxation decay curves were fitted with mono-exponential decay models of the functional form $A \cdot \exp \left(-\tau_{\text {echo }} / B\right)$. The experimental error on the transverse relaxation times have been extracted with bootstrapping methods using 200 iterations. Homogeneous linewidths have been obtained from the fitted transverse relaxation times using $\Delta^{\text {homo }}=1 /\left(\pi T_{2}^{\prime}\right)$. Experimental errors thereon have been obtained applying Gaussian error propagation on the obtained standard deviation for the transverse relaxation times. Error bars are reported as $2 \sigma$, where $\sigma$ denotes the experimental error. Total linewidths $\Delta^{\text {total }}$ as well as $J$-coupling constants have been obtained via line-shape simulations using dmfit (version 2019). ${ }^{82}$

\section{DFT calculations}

DFT calculations were performed with TURBOMOLE ${ }^{83}$ version 6.4.0. Magnetic shieldings were calculated within the GIAO framework on a B3-LYP ${ }^{84} /$ def2-TZVP ${ }^{85}$ level of theory. An energy convergence criterion of $10^{-7} E_{\mathrm{h}}$ was used in the SCF calculations. The integration grid was set to $\mathrm{m} 4$. The coordinates of a monomeric and dimeric structure of $\mathbf{1}$ were taken from the single crystal structure and used without further geometry optimization.

\section{Semi-classical calculations}

For all relevant details refer to the Section S1 (ESI $\dagger$ ).

\section{Results and discussion}

Scheme 1 outlines the four PH-containing phosphane and phosphonium compounds selected for our study, which originated from phosphorus/boron FLP chemistry. The corresponding $[\mathrm{P}] \mathrm{H}$ and $[\mathrm{P}] \mathrm{H}_{2}$ units, respectively, are highlighted in red. Their preparation and characterization in solution have been reported. ${ }^{77,78}$ The phosphonium-borate heterocycle $\mathbf{1}$ is the rearrangement product of the phosphonium-borate $2 .^{77} 1$ contains a single $[\mathrm{P}] \mathrm{H}$ unit, whereas 2 possesses a $[\mathrm{P}] \mathrm{H}_{2}$ group and we will assess whether fast MAS experiments allow a distinction of the two phosphonium protons. The hydroboration reaction of $\mathrm{Mes}^{*} \mathrm{P}(\mathrm{H})$ vinyl 3 with Piers Borane $\left[\mathrm{HB}\left(\mathrm{C}_{6} \mathrm{~F}_{5}\right)_{2}\right]$ gave the cyclotrimeric FLP associate 4 which in solution is in a temperature-dependent equilibrium with the corresponding monomer. ${ }^{77}$ In the crystal structure of 4 the three $\mathrm{P}-\mathrm{H}$ vectors are all-cis arranged and the molecule slightly deviates from $C_{3}$-symmetry ${ }^{77}$ and should thus give three distinct resonances for the three monomeric units in solid-state NMR spectra. While a single-crystal structure of the heterocycle 1 exists as well, the $\mathrm{X}$-ray structures of compounds 2 and 3 remain unknown.

\section{Resolution characterization in $1 \mathrm{D}$ proton-detected experiments under fast MAS}

Fig. 1a, b, e and f show the MAS-dependent proton-detected Hahn echo spectra of compounds 1-4 recorded with MAS

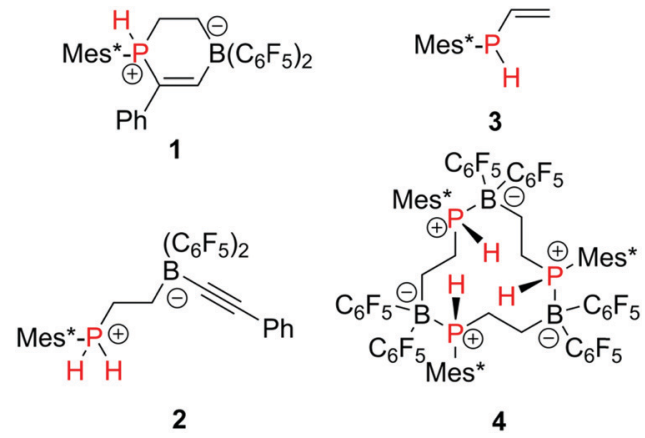

Scheme 1 Depiction of the compounds studied herein (1, 2 and $\mathbf{4}$ were described in ref. 77 and $\mathbf{3}$ in ref. 78) The investigated $\mathrm{H}$-P connectivities are highlighted in red. Note that compound 4 exists solely as a trimer in solution only at low temperatures. ${ }^{77}$ Mes* stands for 2,4,6-tri(tertbutyl)phenyl.

frequencies ranging in-between 60 to $100 \mathrm{kHz}$ and measured at 20.0 $\mathrm{T}$ external magnetic-field strength (corresponding to $850 \mathrm{MHz}$ proton Larmor frequency). The experiments were performed in $0.7 \mathrm{~mm}$ solid-state NMR rotors using less than $500 \mu \mathrm{g}$ of material. The resolution in such spectra increases significantly with faster MAS as recently shown for $\mathrm{FLP}-\mathrm{H}_{2}$ splitting products ${ }^{15,62}$ due to a coherent reduction of the homogeneous proton line broadening. ${ }^{6,7}$ We have determined the homogeneous proton line broadening at $100 \mathrm{kHz}$ MAS by measuring transverse proton relaxation times $T_{2}^{\prime}\left({ }^{1} \mathrm{H}\right)$ (relaxation traces and corresponding mono-exponential fits are given in Fig. S1, ESI $\dagger$ ) and using the relation $\Delta^{\text {homo }}\left({ }^{1} \mathrm{H}\right)=1 /\left(\pi T_{2}^{\prime}\left({ }^{1} \mathrm{H}\right)\right)$. The sitespecifically extracted $\Delta^{\text {homo }}\left({ }^{1} \mathrm{H}\right)$-values for the four compounds are given in Fig. 1c, $d, g$ and $h$. For all compounds, the $\Delta^{\text {homo }}\left({ }^{1} \mathrm{H}\right)$-values for aromatic as well as methyl protons are smaller than $100 \mathrm{~Hz}$ and therefore a significant contribution to the experimental proton linewidth is attributed to inhomogeneous broadening effects, e.g. chemical-shift distribution effects within the studied microcrystalline samples (for a site-specific quantification of the linewidths contributions in compound $\mathbf{1}$ refer to Table S1, ESI $\dagger$ ). The situation is different for methylene groups $\left(\mathrm{PCH}_{2}\right.$ and $\mathrm{BCH}_{2}$ groups in our examples), for which even at $100 \mathrm{kHz}$ MAS the homogeneous line broadening contribution is ranging in-between $300-400 \mathrm{~Hz}$ illustrating that faster MAS would further decrease the proton linewidths. These protons are in a stronger coupling regime and their resolution is expected to show the steepest improvement with an increase in MAS frequency or external magnetic field strength. ${ }^{7,8,67,70,86}$ For instance the use of the recently installed $28.2 \mathrm{~T}(1200 \mathrm{MHz})$ magnet ${ }^{67,86}$ allows to push the resolution for such resonances even further as it becomes evident by comparing the better peak separation and line narrowing in the ${ }^{1} \mathrm{H}$-MAS spectra of compound 1 between $850 \mathrm{MHz}$ and $1200 \mathrm{MHz}$ in Fig. S2 (ESI $\dagger$ ). The quadrupolar boron nucleus causing quadrupolar relaxation (scalar relaxation of the second kind) ${ }^{87,88}$ can lead to an additional source for homogeneous proton line broadening. 

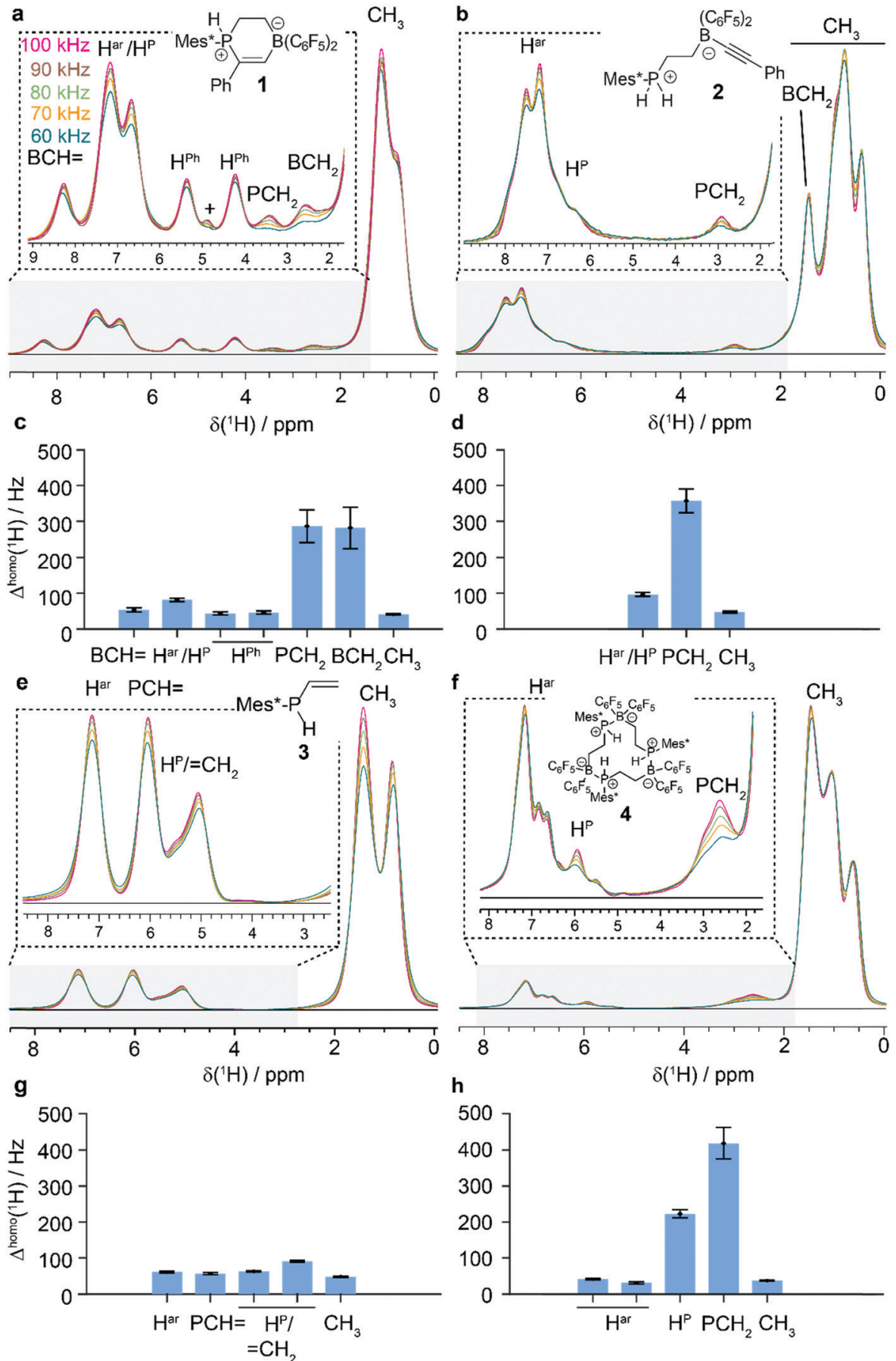

Fig. 1 Proton-detected MAS NMR of compounds 1 to $\mathbf{4}$. a MAS-dependent ${ }^{1} \mathrm{H}$ spectra of $\mathbf{1}$ (a), $\mathbf{2}$ (b), $\mathbf{3}$ (e) and 4 (f) (chemical structures see insets) recorded with spinning frequencies varied between 60 and $100 \mathrm{kHz}$ at $20.0 \mathrm{~T}$. The homogeneous ${ }^{1} \mathrm{H}$ linewidths of the respective subunits are given in (c) for $\mathbf{1}$, in (d) for $\mathbf{2}$, in (g) for $\mathbf{3}$ and in (h) for $\mathbf{4}$. + marks an impurity, possibly water.

Proton-detected 2D homonuclear correlation spectra initiate NMR resonance assignment and reveal intermolecular ringcurrent effects

We have additionally recorded spin-diffusion (SD)-based 2D homonuclear proton correlation spectra at $100 \mathrm{kHz}$ MAS (Fig. 2, the mixing time was set to $50 \mathrm{~ms}$ ). Such spectra reveal spatial proximities among protons and thus can be used for resonance assignment ${ }^{61}$ as well as structural characterization. ${ }^{89-91}$ We are thus able to characterize such compounds in the solid state, similar to studies in solution using the dissolved compounds. A particular challenge arises from intermolecular contacts present in the solid state that potentially can also generate cross peaks in such 2D spectra, which are not observed in solution. For the purposes herein, we transferred the resonance 

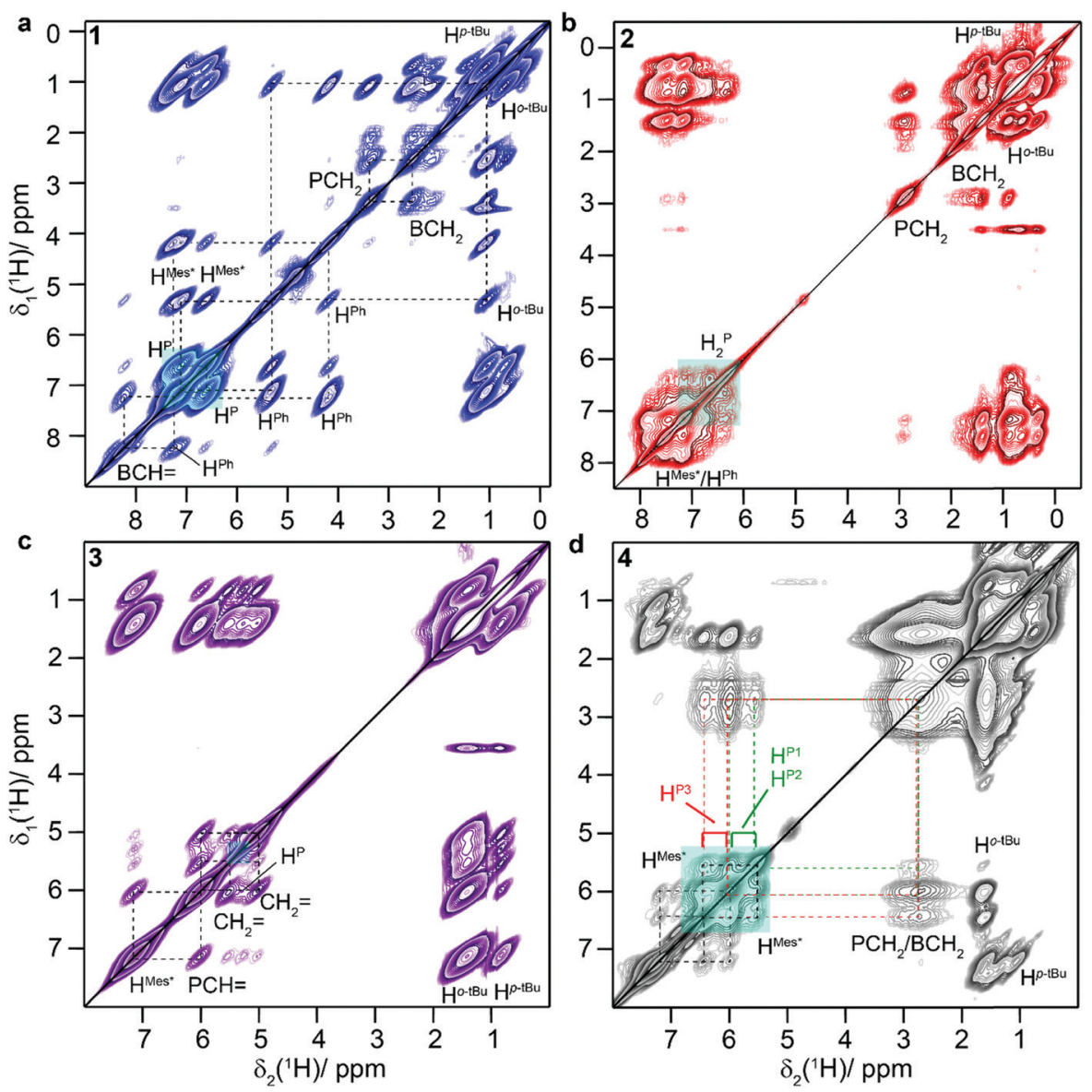

Fig. 2 Initiating resonance assignment by proton-detected NMR at fast MAS. ${ }^{1} \mathrm{H}-{ }^{1} \mathrm{H} 50 \mathrm{~ms}$ SD spectrum of compounds 1 (a), 2 (b), 3 (c) and 4 (d) recorded at $20.0 \mathrm{~T}$ and a MAS frequency of $100 \mathrm{kHz}$. Representative resonance assignments and correlations are plotted on the spectra. The phosphane/phosphonium proton resonances are highlighted in cyan.

assignments obtained in solution ${ }^{77,78}$ and verified them with the help of the 2D spectra in the solid state.

The $2 \mathrm{D}{ }^{1} \mathrm{H}^{-1} \mathrm{H}$ SD spectra in Fig. 2 show indeed sufficient resolution for the assignment of the respective units (some representative assignments and connectivities are plotted on the spectra). A particularly interesting effect is found in heterocycle $1 .{ }^{1} \mathrm{H}$ resonances are detected in the ${ }^{1} \mathrm{H}$ MAS spectra at 4.2 and 5.3 ppm (Fig. 1a) absent in the solution-state NMR spectra which can be assigned to phenyl protons (Fig. 2a and Fig. S3, ESI $\dagger$ ), shifting to lower ppm-values as a consequence of intermolecular ring-current effects caused by delocalized $\pi$-electrons of the aromatic rings. ${ }^{92}$ This is further corroborated by the calculation of magnetic shieldings using density functional theory (DFT). Such calculations were performed using atomic coordinates of a monomer and a dimer, the latter to account for the intermolecular packing effects (the coordinates were taken from the single crystal structure ${ }^{77}$ ). And indeed, two resonances of the phenyl ring are significantly more shielded by 1.7 and $1.2 \mathrm{ppm}$ in the dimer (H1 and H2, see Fig. 3a and b) caused by intermolecular packing effects. We further calculated the shielding effect experienced by the phenyl protons due to intermolecular ring current effects with a phenyl and a $\mathrm{C}_{6} \mathrm{~F}_{5}$ group of a neighboring molecule using the semi-classical
Johnson-Bovey equation. ${ }^{93,94}$ Also using this approach, the $\mathrm{H} 1$ and $\mathrm{H} 2$ resonances are predicted to shift to lower ppm-values $(-1.5 \mathrm{ppm}$ for $\mathrm{H} 1$ and $\mathrm{H} 2)$. For more details see the Section S1 and Fig. S4 and S5 (ESI $\dagger$ ) therein.

Particularly the availability of high static magnetic fields nowadays allows for recording proton-detected ${ }^{1} \mathrm{H},{ }^{13} \mathrm{C}$ correlation experiments using samples with natural abundant ${ }^{13} \mathrm{C}$ only. We used such an experiment to prove the connectivity of the two shielded protons at 4.2 and $5.3 \mathrm{ppm}$ based on their ${ }^{13} \mathrm{C}$ shift at $c a .130 \mathrm{ppm}$ which is characteristic for aromatic carbon atoms (see Fig. 3c). The correlation experiment has been recorded in less than a day and shows a good signal-to-noise ratio. Such intermolecular ring-current effects and their influence on proton chemical-shift values has been observed in other contexts before (see e.g. ref. 61, 92 and 95), but illustrates again the great care that has to be undertaken in assigning proton solid-state NMR chemical shifts, even when solutionstate shifts are available. Most compounds show tilted, elongated cross-peaks indicative for correlated chemical shifts (for the most illustrative example see Fig. 2a; compound 1). Whether this observation is related to chemical-shift distribution effects caused by structural heterogeneities (e.g. slight structural perturbations in the aromatic units) or so-called 


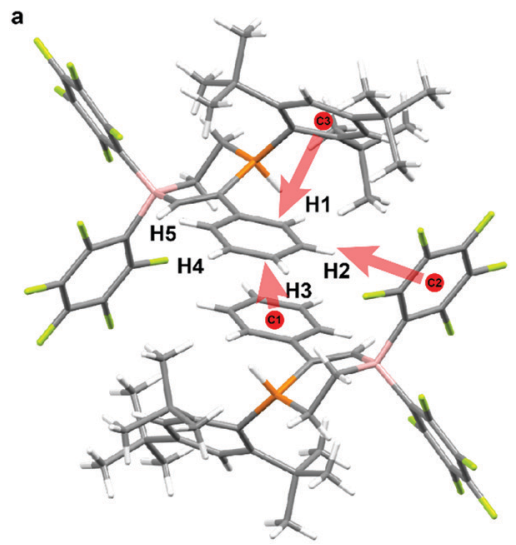

\begin{tabular}{|c|c|c|c|c|c|}
\hline Atom & $\begin{array}{c}\Delta \delta^{\mathrm{JB}} / \mathbf{p p m} \\
\mathrm{Ph}-\mathrm{C1}_{1}\end{array}$ & $\begin{array}{c}\Delta \delta^{\mathrm{J}} / \mathrm{ppm} \\
\mathrm{C}_{6} \mathrm{~F}_{5}=\mathrm{C2}\end{array}$ & $\begin{array}{l}\Delta \delta^{\mathrm{JB}} / \mathrm{ppm} \\
\mathrm{Mes}^{\star}-\mathrm{C} 3\end{array}$ & $\begin{array}{c}\Delta \delta^{\mathrm{JB}}{ }^{\mathrm{tot}}{ }^{\prime} \\
\mathrm{ppm}\end{array}$ & $\begin{array}{l}\Delta \delta^{\mathrm{DFT} /} \\
\mathrm{ppm}\end{array}$ \\
\hline H1 & -1.31 & -0.21 & -1.87 & -3.39 & -1.67 \\
\hline H2 & -0.63 & -0.82 & -0.60 & -2.05 & -1.23 \\
\hline H3 & -0.14 & -0.29 & -0.22 & -0.65 & -0.07 \\
\hline H4 & -0.02 & -0.08 & -0.18 & -0.28 & -0.19 \\
\hline H5 & -0.14 & -0.05 & -0.23 & -0.42 & -0.41 \\
\hline \multicolumn{5}{|c|}{ c $\mathrm{NA}-\mathrm{hCH}, 1200 \mathrm{MHz}, 100 \mathrm{kHz}$ MAS } & $30 \stackrel{20}{0}$ \\
\hline 8 & 6 & $\begin{array}{cc}5 & 4 \\
\delta_{1}\left({ }^{1} \mathrm{H}\right) / \mathrm{ppm}\end{array}$ & 3 & 2 & \\
\hline
\end{tabular}

Fig. 3 Intermolecular ring-current effects shift some aromatic proton resonances in the solid state to lower ppm-values. (a) Intermolecular packing of 1 as observed in the single crystal structure. The phenyl ring protons ( $\mathrm{H} 1-\mathrm{H} 5)$ are affected by intramolecular (ring with centroid $\mathrm{C} 3$ ) and intermolecular ring current effects (rings with $\mathrm{C} 1$ and $\mathrm{C} 2$ centroids). (b) Calculated chemical-shift changes caused by ring-current effects using the Jonson-Bovey equation for the phenyl group protons H1-H5. Chemical-shift differences between the monomer and dimer as obtained by DFT calculations (def2-TZVP/B3-LYP). (c) Aromatic region of a natural abundance (NA)-hCH correlation spectrum of 1 recorded at $28.2 \mathrm{~T}$ and $100 \mathrm{kHz}$ MAS.

anisotropic bulk magnetic susceptibility effects, ${ }^{68-71}$ in which the isotropic component of the magnetic susceptibility between different crystallites differs leading under MAS to crystalliteorientation specific line shifts, ${ }^{70}$ remains elusive. The $\mathrm{H}^{\mathrm{P}}$ region is highlighted in cyan in Fig. 2 and reveals significant spectral overlap with aromatic protons requiring additional spectroscopic tools to unambiguously identify them. In the $2 \mathrm{D}$ ${ }^{1} \mathrm{H}-{ }^{1} \mathrm{H}$ SD spectrum of the cyclotrimeric FLP-associate 4 (Fig. 2d) two overlapping doublets at around $6 \mathrm{ppm}$ are observed (the spectra were recorded without ${ }^{31} \mathrm{P}$ decoupling during detection such that one-bond ${ }^{1} J\left({ }^{31} \mathrm{P}-{ }^{1} \mathrm{H}\right)$-couplings around $500 \mathrm{~Hz}$ remain visible; see also Fig. 1f and Fig. S6 for the respective ${ }^{31} \mathrm{P}$-decoupled $1 \mathrm{D}$ spectra, ESI $\dagger$ ) which are assigned to $\mathrm{H}^{\mathrm{P}}$ protons. Based on the single crystal structure, in which all three P-B FLP monomers are crystallographically distinct, three $\mathrm{H}^{\mathrm{P}}$ doublets should appear in the spectra, out of which two can be resolved in the 2D spectrum (Fig. 2d). The observation of cross-peaks indicating spatial proximity between the $\mathrm{H}^{\mathrm{P}}$ protons indeed suggests that we can distinguish the distinct monomeric units within the cyclotrimeric assembly (the $\mathrm{H}^{\mathrm{P}}-\mathrm{H}^{\mathrm{P}}$ distances are determined to be $4.8 \AA\left(\mathrm{H}^{\mathrm{P} 1}-\mathrm{H}^{\mathrm{P} 2}\right)$, $4.9 \AA\left(\mathrm{H}^{\mathrm{P} 2}-\mathrm{H}^{\mathrm{P} 3}\right), 5.0 \AA\left(\mathrm{H}^{\mathrm{P} 1}-\mathrm{H}^{\mathrm{P} 3}\right)$ from the $\mathrm{X}$-ray structure $\left.{ }^{77}\right)$.

\section{Proton-phosphorus connectivities revealed in proton-detected hPH spectra}

Next, we were interested in whether the $\mathrm{H}^{\mathrm{P}}$ protons can be selectively excited in spin-filtering experiments, in which two proton-phosphorus cross-polarization (CP) steps are applied (the experiment is denoted with $\mathrm{hPH}$ in the following; see Fig. S7 for the pulse sequence, ESI $\dagger$ ). We have recently presented the first hPH correlation spectrum recorded at $100 \mathrm{kHz}$ MAS in the context of a large motor protein coordinating to DNA and ADP to probe hydrogen bonding. ${ }^{11}$ To establish and setup such experiments, we have chosen a small model compound as an external standard, namely the phosphorylated amino acid tyrosine (ortho-phospho-tyrosine) which has already been subject to solid-state NMR studies. ${ }^{96,97}$ Figure S8 summarizes the ${ }^{1} \mathrm{H}$ MAS spectra, the proton line broadening contributions measured at $100 \mathrm{kHz}$ MAS as well as the hPH spectra (for more details see the Section S2, ESI $\dagger$ ).

Such experiments were then extended to compounds 1-4. One-dimensional ${ }^{31} \mathrm{P}$-detected CP MAS spectra are presented in Fig. 4 (right column) and Fig. 5 (right column) for compounds 1-3 and 4, respectively. The necessity of using hPH filtering for resolving overlap issues and precisely probing ${ }^{31} \mathrm{P}-{ }^{1} \mathrm{H}$ connectivities is illustrated in Fig. S9 (ESI $\dagger$ ), where the onedimensional CP-hPH spectra are directly overlapped with the ${ }^{1} \mathrm{H}$-MAS spectra at $100 \mathrm{kHz}$. The heterocycle 1 and its precursor 2 show a single ${ }^{31} \mathrm{P}$ resonance $(-4.6$ and $-23.5 \mathrm{ppm}$, respectively) as expected, whereas the vinyl-phosphane 3 reveals four resonances $(-67.6,-68.5,-69.3$ and $-70.1 \mathrm{ppm})$ with an approximate $1: 1: 1: 1$ ratio, pointing most likely to four crystallographically distinct molecules in the asymmetric unit. Only a single resonance is detected in solution (for a summary of all extracted ${ }^{31} \mathrm{P}$ chemical-shift values and one-bond $J$-couplings as well as a comparison with solution-state NMR data refer also to Table 1). The ${ }^{31} \mathrm{P}$ CP MAS spectrum of the cyclotrimeric FLPassociate 4 reveals three ${ }^{31} \mathrm{P}$ resonances (P1: $-6.3 \mathrm{ppm}, \mathrm{P} 2$ :

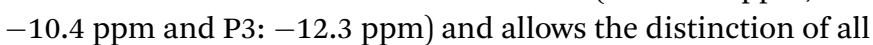
three crystallographically inequivalent monomer units. In solution, only a single ${ }^{31} \mathrm{P}$ resonance is observed for the trimeric system even at low temperature (Table 1).

The 2D hPH spectra of compounds 1-3 are given in Fig. 4, either recorded with low-power ${ }^{31} \mathrm{P}$ WALTZ-64 decoupling during acquisition (spectra color-coded in red) or without ${ }^{31} \mathrm{P}$ decoupling (blue-colored spectra). Fig. 4a shows the spectra for the phosphonium-borate heterocycle $\mathbf{1}$ with the most intense cross-peak observed for the $\mathrm{H}^{\mathrm{P}}$ species. As expected for a covalently bound phosphonium proton, a doublet is observed in the non-decoupled spectrum and the ${ }^{1} J\left({ }^{31} \mathrm{P}-{ }^{1} \mathrm{H}\right)$ $J$-coupling constant is determined to be $462 \mathrm{~Hz}$. As a matter of fact, a singlet is observed in the ${ }^{31} \mathrm{P}$-decoupled spectra. 

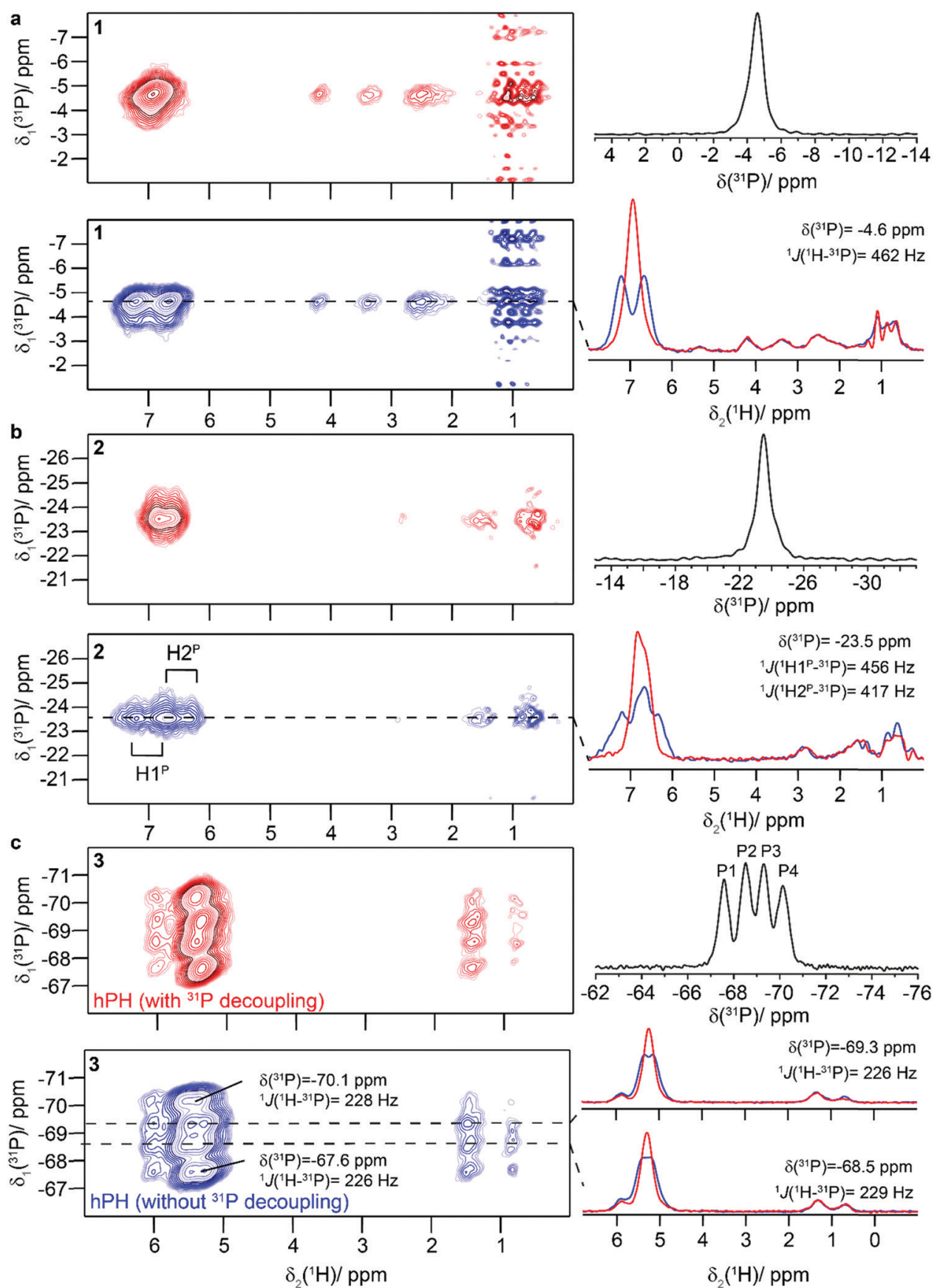

Fig. 4 Probing spatial proximities and ${ }^{1} \mathrm{H}-{ }^{31} \mathrm{P}$ J-couplings in proton-detected hPH correlation spectra. hPH correlation spectra of $\mathbf{1}$ (a), 2 (b), $\mathbf{3}$ (c) recorded with low-power ${ }^{31}$ P WALTZ-64 decoupling during detection (red) and without decoupling (blue). Traces along F2 are given on the right of the spectrum (for 3 only two characteristic traces are shown). All spectra were recorded at $20.0 \mathrm{~T}$ and a MAS frequency of $100 \mathrm{kHz}$. The ${ }^{31} \mathrm{P}$ CPMAS spectra are given in black on the top right of each panel. Compound 1 shows significant t1-noise for the methyl groups pointing to their longer transverse coherence lifetimes.

Fig. $4 \mathrm{~b}$ shows the hPH spectrum of the phosphonium-borate 2 with two overlapping doublets assigned to the $[\mathrm{P}] \mathrm{H}_{2}$ species with ${ }^{1} J\left({ }^{31} \mathrm{P}-{ }^{1} \mathrm{H}\right) J$-coupling constants of 417 and $456 \mathrm{~Hz}$. The ${ }^{31} \mathrm{P}$ decoupled spectrum (red spectrum in Fig. 4b) clearly shows two well-resolved proton resonances assigned to the two phosphonium protons. A particularly challenging system is the vinylphosphane 3 due to the four structurally distinct molecules detected in the ${ }^{31} \mathrm{P}$ CP MAS spectra. It was possible for all four ${ }^{31} \mathrm{P}$ resonances to identify the corresponding $\mathrm{H}^{\mathrm{P}}$ protons in the respective hPH spectra, and line-shape simulations of the traces along $\mathrm{F} 2$ allow the determination of the ${ }^{1} J\left({ }^{31} \mathrm{P}-{ }^{1} \mathrm{H}\right)$ $J$-coupling constants in the range between $226-229 \mathrm{~Hz}$.

The hPH spectra of the cyclotrimeric FLP-associate 4 are shown in Fig. 5. For all three ${ }^{31} \mathrm{P}$ resonances a doublet is 


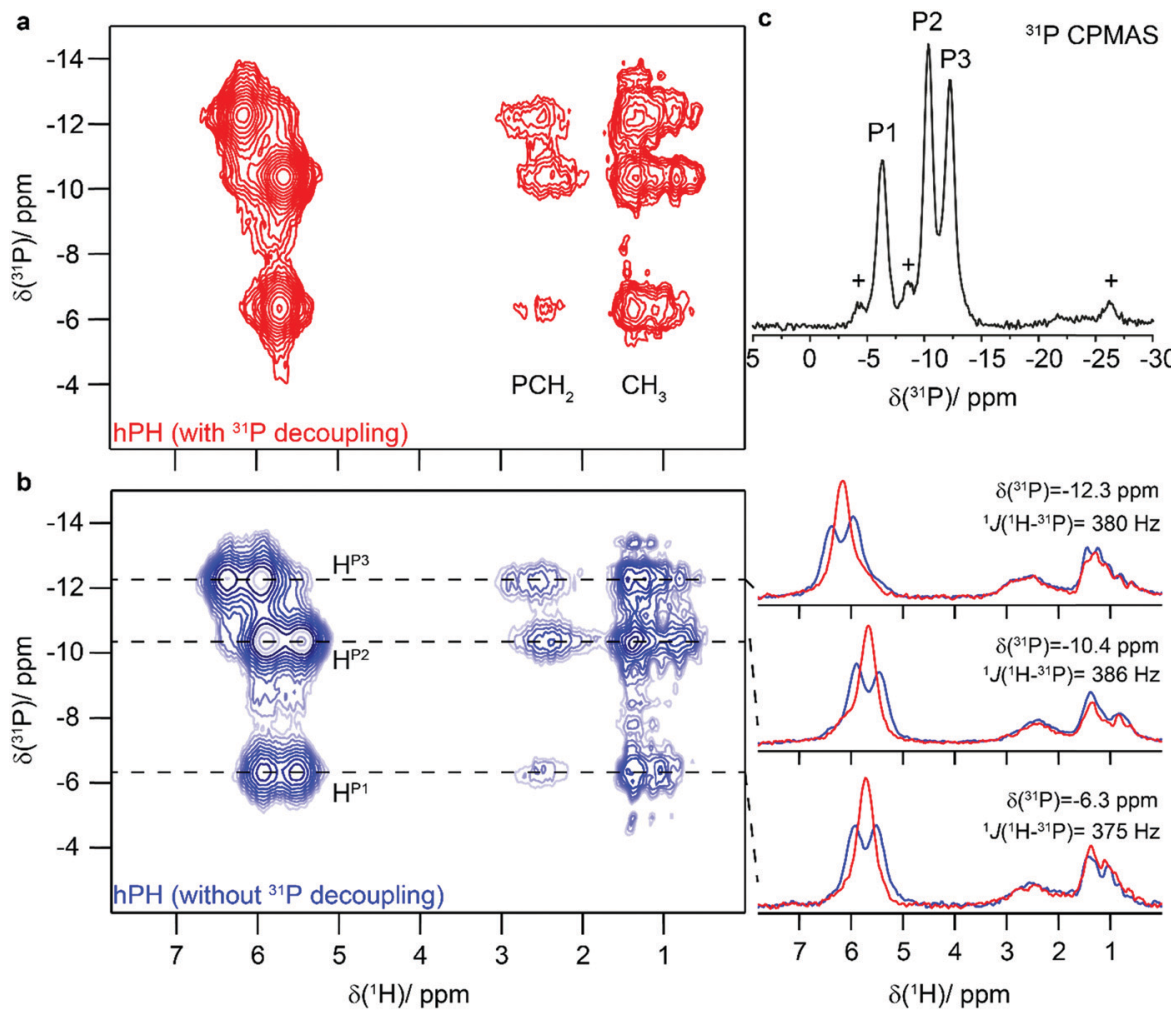

Fig. 5 Probing spatial proximities and ${ }^{1} \mathrm{H}-{ }^{31} \mathrm{P}$ J-couplings in $\mathrm{hPH}$ correlation spectra. a hPH correlation spectrum of 4 recorded with low-power ${ }^{31} \mathrm{P}$ WALTZ-64 decoupling during detection. $\mathrm{b}$ Same experiment than described under a, but without any ${ }^{31} \mathrm{P}$ decoupling during detection. Traces along F2 for the three ${ }^{31} \mathrm{P}$ chemical shifts are given on the right of the spectrum. All spectra were recorded at $20.0 \mathrm{~T}$ and a MAS frequency of $100 \mathrm{kHz}$. $\mathrm{C}^{31} \mathrm{P} C \mathrm{CP}$ MAS spectrum of 4. + mark minor impurities.

Table 1 Collection of solid-state phosphorous chemical-shift values, $\left({ }^{31} \mathrm{P}\right)$, and corresponding one-bond $\mathrm{J}$-couplings, ${ }^{1} \mathrm{~J}\left({ }^{31} \mathrm{P}-{ }^{1} \mathrm{H}\right)$, determined in this work for compounds 1-4 and comparison with their corresponding values obtained from solution-state NMR

\begin{tabular}{lll}
\hline & $\delta^{\text {solid }}\left({ }^{31} \mathrm{P}\right) / \mathrm{ppm}\left(\delta^{\text {solution }}\left({ }^{31} \mathrm{P}\right) / \mathrm{ppm}\right)$ & ${ }^{1} J^{\text {solid }}\left({ }^{31} \mathrm{P}-{ }^{1} \mathrm{H}\right) / \mathrm{Hz}\left({ }^{1} J^{\text {solution }}\left({ }^{31} \mathrm{P}-{ }^{1} \mathrm{H}\right) / \mathrm{Hz}\right)$ \\
\hline $\mathbf{1}$ & $-4.6\left(13.4^{a}\right)$ & $462\left(460^{a}\right)$ \\
$\mathbf{2}$ & $-23.5\left(-21.8^{a}\right)$ & $456 / 417\left(480^{a}\right)$ \\
$\mathbf{3}$ & $-67.6 ;-68.5 ;-69.3 ;-70.1\left(-67.6^{b}\right)$ & $226 ; 229 ; 226 ; 228\left(233^{b}\right)$ \\
$\mathbf{4}$ & $-6.3 ;-10.4 ;-12.3\left(-12.8^{a}\right)$ & $375 ; 386 ; 380\left(375^{a}\right)$ \\
${ }^{a}$ Taken from ref. 77 and. ${ }^{b}$ Taken from ref. 78.
\end{tabular}

observed in the non-decoupled hPH spectra $\left({ }^{1} J\left({ }^{31} \mathrm{P}-{ }^{1} \mathrm{H}\right)\right.$-values between 375 and $386 \mathrm{~Hz}$, blue spectrum) which collapses upon ${ }^{31} \mathrm{P}$-decoupling (red spectrum). We thus demonstrate that a solid-state NMR spectroscopic distinction of the three $[\mathrm{P}] \mathrm{H}$ entities in proton-detected NMR spectra became possible due to recent progress in NMR experiments at fast MAS $(100 \mathrm{kHz})$ and in NMR probe design (introduction of a ${ }^{31} \mathrm{P}$ channel in $0.7 \mathrm{~mm}$ probes for $20.0 \mathrm{~T}$ ) significantly extending the use of NMR in characterizing FLP entities in the solid state.

\section{Conclusions}

We have explored how recent improvements in proton-detected NMR, particularly fast MAS experiments, can be used to structurally characterize phosphonium and phosphane systems, as for example related to the strongly evolving field of Frustrated Lewis Pairs. Fast MAS experiments significantly reduce the homogeneous proton linewidths in such compounds which is particularly apparent for strongly coupled methylene protons. MAS experiments at $100 \mathrm{kHz}$ and $20.0 \mathrm{~T}$ magnetic-field strength initiate resonance assignment by proton-detected NMR, for instance in spin-diffusion based homonuclear $2 \mathrm{D}{ }^{1} \mathrm{H}-{ }^{1} \mathrm{H}$ spectra. Solid-state packing effects can lead to unusual proton chemical-shift values due to intermolecular ring-current effects, making assignment transfer from solution protonchemical shift values not straightforward. In such cases using ${ }^{1} \mathrm{H}-{ }^{1} \mathrm{H}$ and particularly also hCH spectra, the latter recorded on a natural abundant sample at the highest steady-state magnetic field available in these days (28.2 T), can greatly lift remaining ambiguities. The unambiguous spectroscopic identification of $[\mathrm{P}] \mathrm{H}$ or even $[\mathrm{P}] \mathrm{H}_{2}$ protons is achieved by introducing ${ }^{31} \mathrm{P}$ nuclei 
as an additional player in fast MAS experiments at high magnetic fields. We implemented 2D hPH correlation spectra which have allowed us to extract ${ }^{1} J\left({ }^{31} \mathrm{P}-{ }^{1} \mathrm{H}\right) J$-coupling constants in ${ }^{1} \mathrm{H}$ MAS spectra in a series of phosphane and phosphoniumborate species. We demonstrate that typical strengths of solution-state NMR in multinuclear NMR studies to characterize organic molecules can be transferred nowadays also to proton-detected solid-state NMR, thus closing more and more the gap between solution- and solid-state NMR. Solid-state NMR in contrast to solution-state NMR is able to distinguish crystallographically distinct entities (e.g. the four molecules in the asymmetric unit observed for a vinyl-phosphane or the three monomers in a cyclotrimeric FLP-associate).

\section{Author contributions}

A. A. M. and T. W. performed the NMR experiments and Q. S. prepared the samples. J. Z. performed the semi-classical calculations; T. W. carried out the DFT calculations. A. A. M., J. Z., G. K., G. E. and T. W. analysed the data. T. W. designed and supervised the research. T. W. has written the initial draft, which was edited by all co-authors.

\section{Conflicts of interest}

The authors declare no conflict of interest.

\section{Acknowledgements}

This work was supported by the Deutsche Forschungsgemeinschaft (DFG, German Research Foundation, project number 455240421 and Heisenberg fellowship, project number 455238107, T. W.) and ETH Zürich (ETH Research Grant ETH43 17-2, T. W.). T. W. acknowledges the Max Planck Society for funding and acknowledges helpful discussions with Prof. Matthias Ernst and Prof. Beat H. Meier (ETH Zürich, Switzerland). TW acknowledges Prof. Beat H. Meier for providing measurement time for the project and Daniel Zindel (ETH Zürich, Switzerland) for maintaining the glove box. Open Access funding provided by the Max Planck Society.

\section{References}

1 W. Zhang, S. Xu, X. Han and X. Bao, Chem. Soc. Rev., 2012, 41, 192-210.

2 C. Copéret, W.-C. Liao, C. P. Gordon and T.-C. Ong, J. Am. Chem. Soc., 2017, 139, 10588-10596.

3 J. G. Schiffmann, F. Emmerling, I. C. B. Martins and L. Van Wüllen, Solid State Nucl. Magn. Reson., 2020, 109, 101687.

4 Y. Xu, L. Champion, B. Gabidullin and D. L. Bryce, Chem. Commun., 2017, 53, 9930-9933.

5 S. Kaabel, R. S. Stein, M. Fomitšenko, I. Järving, T. Friščić and R. Aav, Angew. Chem., Int. Ed., 2019, 58, 6230-6234.
6 U. Sternberg, R. Witter, I. Kuprov, J. M. Lamley, A. Oss, J. R. Lewandowski and A. Samoson, J. Magn. Reson., 2018, 291, 32-39.

7 A. A. Malar, S. Smith-Penzel, G. M. Camenisch, T. Wiegand, A. Samoson, A. Bockmann, M. Ernst and B. H. Meier, Phys. Chem. Chem. Phys., 2019, 21, 18850-18865.

8 M. Chávez, T. Wiegand, A. A. Malär, B. H. Meier and M. Ernst, Magn. Resonance, 2021, 2, 499-509.

9 C. Bornes, M. Sardo, Z. Lin, J. Amelse, A. Fernandes, M. F. Ribeiro, C. Geraldes, J. Rocha and L. Mafra, Chem. Commun., 2019, 55, 12635-12638.

10 L. Mafra, J. Rocha, C. Fernandez and F. A. Almeida Paz, J. Magn. Reson., 2006, 180, 236-244.

11 A. A. Malär, N. Wili, L. A. Völker, M. I. Kozlova, R. Cadalbert, A. Däpp, M. E. Weber, J. Zehnder, G. Jeschke, H. Eckert, A. Böckmann, D. Klose, A. Y. Mulkidjanian, B. H. Meier and T. Wiegand, Nat. Commun., 2021, 12, 5293.

12 L. Mafra, F. A. Almeida Paz, J. Rocha, A. Espina, S. A. Khainakov, J. R. García and C. Fernandez, Chem. Mater., 2005, 17, 6287-6294.

13 T. M. Alam, B. C. Tischendorf and R. K. Brow, Solid State Nucl. Magn. Reson., 2005, 27, 99-111.

14 C. Bornes, M. Fischer, J. A. Amelse, C. F. G. C. Geraldes, J. Rocha and L. Mafra, J. Am. Chem. Soc., 2021, 143, 13616-13623.

15 R. Knitsch, T. Özgün, G.-Q. Chen, G. Kehr, G. Erker, M. R. Hansen and H. Eckert, ChemPhysChem, 2019, 20, 1837-1849.

16 A. G. Webb, J. Magn. Reson., 2013, 229, 55-66.

17 A. Samoson, T. Tuherm, J. Past, A. Reinhold, I. Heinmaa, T. Anupõld, M. E. Smith and K. J. Pike, in eMagRes.

18 D. W. Stephan and G. Erker, Philos. Trans. R. Soc., A, 2017, 375, 20170239.

19 D. W. Stephan and G. Erker, Angew. Chem., Int. Ed., 2015, 54, 6400-6441.

20 P. Spies, G. Erker, G. Kehr, K. Bergander, R. Fröhlich, S. Grimme and D. W. Stephan, Chem. Commun., 2007, 5072-5074.

21 F.-G. Fontaine and D. W. Stephan, Philos. Trans. R. Soc., A, 2017, 375, 20170004.

22 G. Erker, C. R. Chim, 2011, 14, 831-841.

23 D. W. Stephan, Science, 2016, 354, aaf7229.

24 N. Li and W.-X. Zhang, Chin. J. Chem., 2020, 38, 1360-1370. 25 D. W. Stephan, J. Am. Chem. Soc., 2015, 137, 10018-10032.

26 Z. Niu, W. D. C. Bhagya Gunatilleke, Q. Sun, P. C. Lan, J. Perman, J.-G. Ma, Y. Cheng, B. Aguila and S. Ma, Chem, 2018, 4, 2587-2599.

27 D. W. Stephan, Chem, 2020, 6, 1520-1526.

28 D. W. Stephan and G. Erker, Angew. Chem., Int. Ed., 2010, 49, 46-76.

29 Frustrated Lewis Pairs I, Uncovering and Understanding in Topics Curr. Chem., ed. G. Erker and D. W. Stephan, Springer, Heidelberg, New York, Dordrecht, London, 2013.

30 J. Paradies, Coord. Chem. Rev., 2019, 380, 170-183.

31 G. Kehr and G. Erker, Chem. Record, 2017, 17, 803-815.

32 L. Wang, G. Kehr, C. G. Daniliuc, M. Brinkkotter, T. Wiegand, A. L. Wubker, H. Eckert, L. Liu, J. G. Brandenburg, S. Grimme and G. Erker, Chem. Sci., 2018, 9, 4859-4865. 
33 T. Wiegand, H. Eckert, O. Ekkert, R. Fröhlich, G. Kehr, G. Erker and S. Grimme, J. Am. Chem. Soc., 2012, 134, 4236-4249.

34 T. Wiegand, H. Eckert and S. Grimme, Frustrated Lewis Pairs I, Uncovering and Understanding in Topics Curr. Chem., Springer, Berlin Heidelberg, 2013, ch. 386, p. 291.

35 R. Knitsch, M. Brinkkötter, T. Wiegand, G. Kehr, G. Erker, M. R. Hansen and H. Eckert, Molecules, 2020, 25, 1400.

36 T. Wiegand, M. Siedow, H. Eckert, G. Kehr and G. Erker, Isr. J. Chem., 2015, 55, 150-178.

37 J.-Y. Xing, J.-C. Buffet, N. H. Rees, P. Norby and D. O'Hare, Chem. Commun., 2016, 52, 10478-10481.

38 L. Wang, S. Dong, C. G. Daniliuc, L. Liu, S. Grimme, R. Knitsch, H. Eckert, M. R. Hansen, G. Kehr and G. Erker, Chem. Sci., 2018, 9, 1544-1550.

39 M. Erdmann, T. Wiegand, J. Blumenberg, H. Eckert, J. Ren, C. G. Daniliuc, G. Kehr and G. Erker, Dalton Trans., 2014, 43, 15159-15169.

40 U. Yolsal, T. A. R. Horton, M. Wang and M. P. Shaver, J. Am. Chem. Soc., 2021, 143, 12980-12984.

41 U. Yolsal, T. A. R. Horton, M. Wang and M. P. Shaver, Prog. Polym. Sci., 2020, 111, 101313.

42 M. Wang, F. Nudelman, R. R. Matthes and M. P. Shaver, J. Am. Chem. Soc., 2017, 139, 14232-14236.

43 Z. Niu, W. Zhang, P. C. Lan, B. Aguila and S. Ma, Angew. Chem., Int. Ed., 2019, 58, 7420-7424.

44 S. P. Brown, Solid State Nucl. Magn. Reson., 2012, 41, 1-27.

45 A. Samoson, J. Magn. Reson., 2019, 306, 167-172.

46 M. Schledorn, A. A. Malar, A. Torosyan, S. Penzel, D. Klose, A. Oss, M. L. Org, S. Wang, L. Lecoq, R. Cadalbert, A. Samoson, A. Bockmann and B. H. Meier, ChemBioChem, 2020, 21, 2540-2548.

47 E. C.-Y. Yuan, S.-J. Huang, H.-C. Huang, J. Sinkkonen, A. Oss, M.-L. Org, A. Samoson, H.-C. Tai and J. C. C. Chan, Chem. Commun., 2021, 57, 4110-4113.

48 L. B. Andreas, K. Jaudzems, J. Stanek, D. Lalli, A. Bertarello, T. Le Marchand, D. Cala-De Paepe, S. Kotelovica, I. Akopjana, B. Knott, S. Wegner, F. Engelke, A. Lesage, L. Emsley, K. Tars, T. Herrmann and G. Pintacuda, Proc. Natl. Acad. Sci. U. S. A., 2016, 113, 9187-9192.

49 S. K. Vasa, H. Singh, K. Grohe and R. Linser, Angew. Chem., Int. Ed., 2019, 58, 5758-5762.

50 V. Jirasko, A. Lends, N.-A. Lakomek, M.-L. Fogeron, M. E. Weber, A. A. Malär, S. Penzel, R. Bartenschlager, B. H. Meier and A. Böckmann, Angew. Chem., Int. Ed., 2021, 60, 5339-5347.

51 J. Struppe, C. M. Quinn, M. Lu, M. Wang, G. Hou, X. Lu, J. Kraus, L. B. Andreas, J. Stanek, D. Lalli, A. Lesage, G. Pintacuda, W. Maas, A. M. Gronenborn and T. Polenova, Solid State Nucl. Magn. Reson., 2017, 87, 117-125.

52 V. Agarwal, S. Penzel, K. Szekely, R. Cadalbert, E. Testori, A. Oss, J. Past, A. Samoson, M. Ernst, A. Böckmann and B. H. Meier, Angew. Chem., Int. Ed., 2014, 53, 12253-12256.

53 D. Stöppler, A. Macpherson, S. Smith-Penzel, N. Basse, F. Lecomte, H. Deboves, R. D. Taylor, T. Norman, J. Porter, L. C. Waters, M. Westwood, B. Cossins, K. Cain, J. White, R. Griffin, C. Prosser, S. Kelm, A. H. Sullivan, D. Fox, III, M. D. Carr, A. Henry, R. Taylor, B. H. Meier,
H. Oschkinat and A. D. Lawson, PLoS Biol., 2018, 16, e2006192.

54 D. Lacabanne, J. Boudet, A. A. Malar, P. Wu, R. Cadalbert, L. Salmon, F. H. Allain, B. H. Meier and T. Wiegand, J. Phys. Chem. B, 2020, 124, 11089-11097.

55 T. Wiegand, M. Schledorn, A. A. Malär, R. Cadalbert, A. Däpp, L. Terradot, B. H. Meier and A. Böckmann, ChemBioChem, 2020, 21, 324-330.

56 A. Marchanka, J. Stanek, G. Pintacuda and T. Carlomagno, Chem. Commun., 2018, 54, 8972-8975.

57 T. Wiegand, A. A. Malär, R. Cadalbert, M. Ernst, A. Böckmann and B. H. Meier, Front. Mol. Biosci., 2020, 7, 582033.

58 A. A. Malär, L. A. Völker, R. Cadalbert, L. Lecoq, M. Ernst, A. Böckmann, B. H. Meier and T. Wiegand, J. Phys. Chem. B, 2021, 125, 6222-6230.

59 F. M. Paruzzo, B. J. Walder and L. Emsley, J. Magn. Reson., 2019, 305, 131-137.

60 Y. Nishiyama, Solid State Nucl. Magn. Reson., 2016, 78, 24-36.

61 T. Kobayashi, K. Mao, P. Paluch, A. Nowak-Król, J. Sniechowska, Y. Nishiyama, D. T. Gryko, M. J. Potrzebowski and M. Pruski, Angew. Chem., Int. Ed., 2013, 52, 14108-14111.

62 A. A. Malär, S. Dong, G. Kehr, G. Erker, B. H. Meier and T. Wiegand, ChemPhysChem, 2019, 20, 672-679.

63 E. Brunner, D. Freude, B. C. Gerstein and H. Pfeifer, J. Magn. Reson., 1990, 90, 90-99.

64 I. Schnell and H. W. Spiess, J. Magn. Reson., 2001, 151, 153-227.

65 V. E. Zorin, S. P. Brown and P. Hodgkinson, J. Chem. Phys., 2006, 125, 144508.

66 S. Penzel, A. Oss, M. L. Org, A. Samoson, A. Bockmann, M. Ernst and B. H. Meier, J. Biomol. NMR, 2019, 73, 19-29.

67 E. Nimerovsky, K. T. Movellan, X. C. Zhang, M. C. Forster, E. Najbauer, K. Xue, R. Dervişoǧlu, K. Giller, C. Griesinger, S. Becker and L. B. Andreas, Biomolecules, 2021, 11, 752.

68 M. P. Hanrahan, A. Venkatesh, S. L. Carnahan, J. L. Calahan, J. W. Lubach, E. J. Munson and A. J. Rossini, Phys. Chem. Chem. Phys., 2017, 19, 28153-28162.

69 G. Kervern, G. Pintacuda, Y. Zhang, E. Oldfield, C. Roukoss, E. Kuntz, E. Herdtweck, J.-M. Basset, S. Cadars, A. Lesage, C. Copéret and L. Emsley, J. Am. Chem. Soc., 2006, 128, 13545-13552.

70 A. Samoson, T. Tuherm and Z. Gan, Solid State Nucl. Magn. Reson., 2001, 20, 130-136.

71 M. Alla and E. Lippmaa, Chem. Phys. Lett., 1982, 87, 30-33. 72 K. R. Mote, V. Agarwal and P. K. Madhu, Prog. Nucl. Magn. Reson. Spectrosc., 2016, 97, 1-39.

73 J. O. Brauckmann, J. W. G. Janssen and A. P. M. Kentgens, Phys. Chem. Chem. Phys., 2016, 18, 4902-4910.

74 P. Moutzouri, F. M. Paruzzo, B. Simões de Almeida, G. Stevanato and L. Emsley, Angew. Chem., Int. Ed., 2020, 59, 6235-6238.

75 S. P. Brown, Prog. Nucl. Magn. Reson. Spectrosc., 2007, 50, 199-251.

76 P. Moutzouri, B. Simões de Almeida, D. Torodii and L. Emsley, J. Am. Chem. Soc., 2021, 143, 9834-9841. 
77 Q. Sun, C. G. Daniliuc, G. Kehr and G. Erker, Dalton Trans., 2021, 50, 3523-3528.

78 Q. Sun, C. G. Daniliuc, C. Mück-Lichtenfeld, K. Bergander, G. Kehr and G. Erker, J. Am. Chem. Soc., 2020, 142, 17260-17264.

79 T. Stevens, R. Fogh, W. Boucher, V. Higman, F. Eisenmenger, B. Bardiaux, B.-J. van Rossum, H. Oschkinat and E. Laue, J. Biomol. NMR, 2011, 51, 437-447.

80 W. F. Vranken, W. Boucher, T. J. Stevens, R. H. Fogh, A. Pajon, M. Llinas, E. L. Ulrich, J. L. Markley, J. Ionides and E. D. Laue, Proteins: Struct., Funct., Bioinf., 2005, 59, 687-696.

81 R. Fogh, J. Ionides, E. Ulrich, W. Boucher, W. Vranken, J. P. Linge, M. Habeck, W. Rieping, T. N. Bhat, J. Westbrook, K. Henrick, G. Gilliland, H. Berman, J. Thornton, M. Nilges, J. Markley and E. Laue, Nat. Struct. Mol. Biol., 2002, 9, 416-418.

82 D. Massiot, F. Fayon, M. Capron, I. King, S. Le Calvé, B. Alonso, J.-O. Durand, B. Bujoli, Z. Gan and G. Hoatson, Magn. Reson. Chem., 2002, 40, 70-76.

83 R. Ahlrichs, M. Bär, M. Häser, H. Horn and C. Kölmel, Chem. Phys. Lett., 1989, 162, 165-169.

84 P. J. Stephens, F. J. Devlin, C. F. Chabalowski and M. J. Frisch, J. Phys. Chem., 1994, 98, 11623-11627.

85 F. Weigend and R. Ahlrichs, Phys. Chem. Chem. Phys., 2005, 7, 3297-3305.
86 M. Callon, A. A. Malär, S. Pfister, V. Římal, M. E. Weber, T. Wiegand, J. Zehnder, M. Chávez, R. Cadalbert, R. Deb, A. Däpp, M.-L. Fogeron, A. Hunkeler, L. Lecoq, A. Torosyan, D. Zyla, R. Glockshuber, S. Jonas, M. Nassal, M. Ernst, A. Böckmann and B. H. Meier, J. Biomol. NMR, 2021, 75, 255-272. 87 L. G. Werbelow and J. Kowalewski, J. Chem. Phys., 1997, 107, 2775-2781.

88 A. Abragam, The Principles of Nuclear Magnetism, Clarendon Press, 1961.

89 V. Agarwal, J. Magn. Reson., 2020, 311, 106661.

90 B. Elena and L. Emsley, J. Am. Chem. Soc., 2005, 127, 9140-9146.

91 D. L. Bryce, IUCrJ, 2017, 4, 350-359.

92 E. Carignani, S. Borsacchi, J. P. Bradley, S. P. Brown and M. Geppi, J. Phys. Chem. C, 2013, 117, 17731-17740.

93 C. E. J. Jr. and F. A. Bovey, J. Chem. Phys., 1958, 29, 1012-1014.

94 S. J. Perkins and K. Wüthrich, Biochim. Biophys. Acta, Protein Struct., 1979, 576, 409-423.

95 J. Czernek and J. Brus, Int. J. Mol. Sci., 2020, 21, 7908.

96 M. J. Potrzebowski, X. Assfeld, K. Ganicz, S. Olejniczak, A. Cartier, C. Gardiennet and P. Tekely, J. Am. Chem. Soc., 2003, 125, 4223-4232.

97 A. Iuga and E. Brunner, Magn. Reson. Chem., 2004, 42, 369-372. 